\title{
Recognition memory function in early senescent rhesus monkeys
}

\author{
RONALD J. KILLIANY \\ Boston University School of Medicine, Boston, Massachusetts \\ MARK B. MOSS and DOUGLAS L. ROSENE \\ Boston University School of Medicine, Boston, Massachusetts \\ and Yerkes Regional Primate Research Center, Emory University, Atlanta, Georgia \\ and \\ JAMES HERNDON \\ Yerkes Regional Primate Research Center, Emory University, Atlanta, Georgia
}

\begin{abstract}
Assessment of recognition memory was performed in a group of 12 rhesus monkeys, 19-24 years old (an age estimated to be comparable with early senescence in humans-i.e., 60 s to early 70 s). Their performance was compared with that of 14 young adult animals (5-14 years old, comparable to humans from the late teens to early $40 \mathrm{~s}$ ) on two tasks of recognition memory: trial-unique delayed nonmatching to sample (DNMS) and the delayed recognition span task (DRST). The DNMS is a benchmark visual recognition memory task that requires the identification of a novel object when paired with a familiar object that was presented 10 sec earlier. After reaching learning criterion, the memory demands of the task are increased by lengthening the interval between stimulus presentation and recognition up to $600 \mathrm{sec}$ and lengthening the list length of samples presented before recognition up to 10 objects. The DRST is a task used to assess memory capacity by determining memory span for number of stimuli in different stimulus conditions. In the present study, memory span was determined for spatial, color, and object stimuli using both a unique series of stimuli and an embedded repeated series. On DNMS, only 4 of 12 early senescent monkeys were impaired, compared with the range of young adult monkeys in the acquisition of the task, but as a group, they were significantly impaired on the delay and list performance measures. On the DRST, early senescent monkeys, as a group, were impaired on both the spatial condition and the object condition of the task, but not on the color condition. The results reveal a cognitive profile of early senescent monkeys that, unlike monkeys of more advanced age, is characterized by a relatively moderate impairment in recognition memory and memory span.
\end{abstract}

Studies are emerging to suggest that memory function in healthy human subjects may decline as early as 50 years of age (Albert \& Moss, 1999; Gilbert \& Levee, 1971). Relative to the marked memory loss seen with Alzheimer's disease, this memory loss in normal aging is mild (Blackford \& La Rue, 1989; Crook et al., 1986; Smith et al., $1991)$ but, in many individuals, sufficient to affect performance of activities of daily living (La Rue, 1982). The

This research was supported in part by Grant PO1-AG00001 from the National Institute on Aging, Bethesda, $\mathrm{MD}$, and by a research training grant in the structural basis of neurobiology T32-NS07152 from the National Institute of Neurological Disorders and Stroke, Bethesda, MD. In addition, this study was supported by NIH Grant RR-00165 from the National Center for Research Resources to the Yerkes Regional Primate Research Center. Boston University School of Medicine and the Yerkes Regional Primate Research Center are both fully accredited by the American Association for Accreditation of Laboratory Animal Care. The authors thank Tara Moore, Beverly Duryea-Steiger, and John Herndon for their valuable assistance with this project. Correspondence should be addressed to M. B. Moss, Department of Anatomy and Neurobiology, Boston University School of Medicine, 80 East Concord St., Boston, MA 02118 (e-mail: mmoss@cajal-1.bu.edu). important question about these deficits is their underlying neurobiological basis, which is hard to study in humans because of the difficulty in obtaining optimal brain tissue samples at critical time intervals from behaviorally characterized subjects. Recently, the rhesus monkey has proven to be a valuable animal model in which to examine such issues.

In the rhesus monkey, several studies have shown that aged animals evidence impairments on a variety of recognition memory tasks, including delayed nonmatching (Arnstein \& Goldman-Rakic, 1990; Bachevalier, 1993; Moss, Rosene, \& Peters, 1988; Presty et al., 1987; Rapp \& Amaral, 1989, 1991), delayed response (Bachevalier, 1993; Bartus, Fleming, \& Johnson, 1978; Marriott \& Abelson, 1980; Medin \& Davis, 1974; Rapp \& Amaral, 1989), and delayed recognition span (Moss, Killiany, Lai, Rosene, \& Herndon, 1997). However, only a few studies have examined the effects of age on cognitive function with sufficient sample sizes to stratify findings by age. Lifespan data for the rhesus monkey (Tigges, Gordon, McClure, Hall, \& Peters, 1988) show that only $30 \%-40 \%$ of rhesus monkeys attain an age of 19 years, no more than 
$25 \%$ survive to 25 years of age, and few live beyond 30 years of age. With these life-span data and given the fact that the rhesus monkey reaches sexual maturity between 4 and 5 years of age, a conversion ratio of approximately $1: 3$ can be used to estimate human years based on rhesus monkey years. Accordingly, we consider monkeys in the age range of 19-24 as in the early stages of senescence, comparable to humans around 60 to the early $70 \mathrm{~s}$. Monkeys 25-29 years of age might be comparable to humans in their mid 70s to late (i.e., $29=78$ ) 80 s or in a stage of advanced age, and monkeys over 29 years of age would be considered as the oldest of the old, roughly equivalent to humans 90 years of age and above. In order to gain a better understanding of memory function in early human aging, we assessed recognition memory in a group of monkeys 19-24 years old - that is, monkeys considered to be in an early stage of aging - and compared their performance to a group of young adult monkeys (5-14 years of age). The monkeys were assessed on two tasks of recognition memory that have been used with human subjects: the delayed nonmatching-to-sample (DNMS) task and the delayed recognition span task (DRST).

The DNMS task is a benchmark recognition memory task that assesses the subject's ability to differentiate a novel stimulus from a familiar stimulus following a specific delay interval. Various forms of this task have been used to assess memory function in monkeys following specific lesions of the forebrain, including transection of the fornix (Gaffan, 1974; Mahut, Moss, \& Zola-Morgan, 1982; Saunders, Murray, \& Mishkin, 1984), limited or combined lesions of the hippocampus and amygdala (Alverez, Zola-Morgan, \& Squire, 1995; Mahut et al., 1982; Mishkin, 1978; Saunders et al., 1984; Zola-Morgan \& Squire, 1985), or lesions limited to the medial dorsal thalamus (e.g., Aggleton \& Mishkin, 1983). Though originally developed for assessment of memory in animals, the DNMS task has been shown to be sensitive to selected temporal lobe damage in humans (Comparet, Darriet, \& Jaffard, 1992). Consequently, it has also been used to characterize memory impairments in human subjects with amnestic disorders (Squire, Zola-Morgan, \& Chen, 1988), dementia states such as Alzheimer's disease and normal aging (Albert \& Moss, 1984). When later used to assess memory function in aged monkeys, results from several laboratories revealed an impairment in the acquisition and performance component of the DNMS task (Arnstein \& Goldman-Rakic, 1990; Bachevalier, 1993; Moss et al., 1988; Presty et al., 1987; Rapp \& Amaral, 1989, 1991).

The DRST is a short-term memory test that was designed to investigate recognition memory capacity in monkeys following bilateral removal of the hippocampus (Rehbein, 1985). It requires the subject to identify, trial by trial, a new stimulus among an increasing array of serially presented, now-familiar stimuli. The task is administered with different classes of stimulus material using spatial and nonspatial (color, pattern, objects) conditions in order to characterize possible material-specific recognition memory impairments. An expanded form of this task has been used in the same manner to assess recognition memory in a variety of human populations, including those with Alzheimer's disease (Albert \& Moss, 1984; Moss, 1983; Salmon, Granholm, McCullough, Butters, \& Grant, 1989), Huntington's disease or Korsakoff's disease (Moss, Albert, Butters, \& Payne, 1986), and Parkinson's disease (Lange et al., 1992), as well as in normal aging. In normal aged human subjects, recognition memory span measured with the DRST is impaired in several stimulus classes, including spatial position and visual patterns (Inouye, Albert, Mohs, Sun, \& Berkman, 1993; Moss et al., 1986).

\section{METHOD}

\section{Subjects}

The subjects were 26 rhesus monkeys ( 17 males and 9 females; see Table 1), weighing 4.3-14.2 kg. The young adult group, consisting of 14 animals, ranged in age from 5 to 14 years. The early senescent group, consisting of 12 animals, ranged in age from 19 to 24 years. All monkeys in the present study had known birth dates and spent a majority of their adult life coral housed in social groups at the Yerkes Regional Primate Center (YRPRC), and all were housed individually only for $1-3$ years prior to testing. During the time in which the monkeys were housed individually, they were constantly within auditory and visual range of several other monkeys. Feeding took place following testing and water was available continually. Ten of the young adult monkeys (AM35, AM22, AM32, AM39, AM33, AM57, AM66, AM76, AM77, and AM78) and 5 of the early senescent monkeys (AM50, AM63, AM64, AM67, and AM68) were tested at the YRPRC; the remaining monkeys were tested at the primate facility at Boston University Medical Center (BUMC). Testing at both sites was conducted using identical apparatus and procedures. Intertester reliability was monitored by videotaping of the testing sessions at each site. Comparisons of performance between sites show that there was no significant difference between sites in performance of monkeys on the whole or within age groups ( $p \mathrm{~s}>.5)$.

All monkeys received medical examinations, which included serum chemistry, hematology, urine analysis, and fecal analysis before entering the study. In addition, explicit criteria were used to screen the monkeys for history of splenectomy or thymectomy, exposure to radiation, chronic illness including viral or parasitic infections, neurological disease, or chronic drug administration. All monkeys were visually inspected on a daily basis by both animal care personnel and research technicians; on a semiannual basis or as needed, all monkeys were given routine medical exams.

\section{Behavioral Testing}

All monkeys were trained 5 days per week in a Wisconsin General Testing Apparatus (WGTA; Harlow \& Bromer, 1938) in a darkened testing room with white noise used to mask extraneous sounds. The experimenter sat behind a one-way screen facing a $25 \times 70 \mathrm{~cm}$ test tray with one of two configurations of test wells. For initial training and the DNMS task, the tray contained a single row of three wells, $5 \mathrm{~cm}$ in diameter, spaced $15 \mathrm{~cm}$ center to center. For the DRST, there were 18 such wells but arranged in three rows, each containing 6 wells. In addition, the test tray sloped downward at an $8^{\circ}$ angle from the back (closest to the experimenter) toward the monkey. Between trials, the trays were concealed from the monkey by an opaque door. Throughout testing, raisins, M\&Ms, or small pieces of apple were used as rewards.

Prior to the administration of the DNMS task, the monkeys were trained to displace a gray plaque over each of the three wells in order to obtain a food reward for 40 consecutive trials within one testing session. 
Table 1

Subjects

\begin{tabular}{|c|c|c|}
\hline Monkey & Sex & Age at Testing \\
\hline \multicolumn{3}{|c|}{ Young Adult } \\
\hline AM22 & male & 6 \\
\hline AM35 & male & 5 \\
\hline AM76 & female & 5 \\
\hline AM32 & male & 7 \\
\hline AM52 & male & 6 \\
\hline AM47 & male & 8 \\
\hline AM56 & male & 8 \\
\hline AM57 & male & 8 \\
\hline AM 33 & male & 10 \\
\hline AM34 & male & 10 \\
\hline AM39 & male & 10 \\
\hline AM66 & female & 11 \\
\hline AM37 & male & 12 \\
\hline AM49 & male & 14 \\
\hline \multicolumn{3}{|c|}{ Early Senescent } \\
\hline AM24 & female & 19 \\
\hline AM38 & female & 19 \\
\hline AM48 & male & 20 \\
\hline AM50 & male & 20 \\
\hline AM63 & female & 20 \\
\hline AM64 & male & 20 \\
\hline AM67 & male & 20 \\
\hline AM68 & male & 21 \\
\hline AM31 & female & 22 \\
\hline AM26 & female & 23 \\
\hline AM30 & female & 24 \\
\hline AM19 & female & 24 \\
\hline
\end{tabular}

DNMS. Following the administration of the basic task, the monkeys were tested on one of two sets of test conditions. For the first set, the monkeys were tested on delay conditions of $30,60,120$, and $300 \mathrm{sec}$ followed by list lengths of 1, 3, 5, and 10. For the second set, as part of a modified test battery, the monkeys were tested only on delays of 120 and $600 \mathrm{sec}$. During all delay conditions, the monkeys remained in the testing cage within the WGTA.

Basic task. First, a sample object was presented over the central location on the tray. The monkey was required to displace the object to obtain a reward concealed beneath the object. Subsequently, the door blocking the monkey's view of the board was lowered, and, $10 \mathrm{sec}$ later, the recognition trial was begun, with the sample object appearing over one of the lateral wells and a new unfamiliar object appearing over the other lateral well where the single reward was concealed. In order to obtain the reward, the monkey had to recognize the now-familiar original sample object and choose the unfamiliar novel object. Twenty seconds later, a different sample object appeared in the central location, followed $10 \mathrm{sec}$ later by another recognition trial, using new unique objects. The position of the two objects on recognition trials was assigned in a pseudorandom predetermined order (Gellerman, 1933), and a noncorrection procedure was used. Twenty trials a day were administered 5 days per week, and testing continued until the monkey reached a learning criterion of 90 correct responses in 100 consecutive trials or to a maximum of 2,000 trials. Objects were drawn from a pool of 400 objects, and, in each daily session, 40 of the objects were drawn from the pool in a predetermined fashion in order to ensure that the combination of objects used was always trial unique.

Five young monkeys (AM35, AM22, AM32, AM39, and AM33) and 6 early senescent monkeys (AM26, AM30, AM38, AM19, AM24, and AM48) were administered the DNMS task using Performance Set 1 (see delays below); the remaining young adult monkeys and early senescent monkeys were administered Performance Set 2 (see delays below)
Delays. Upon reaching criterion on the basic task, the memory demand on the task was elevated by increasing the delay between the presentation of the sample object and its re-presentation with a novel object either using multiple delays of $30 \mathrm{sec}$ to $60 \mathrm{sec}$ to $120 \mathrm{sec}$ and then to $300 \mathrm{sec}$ in Set 1 or using only the delays of 120 and $600 \mathrm{sec}$ in Set 2. In Set 1, testing was conducted at the 30- and 60sec delays for 20 trials a day for 5 consecutive days and for 10 trials a day for 10 consecutive days at the $120-, 300-$, and $600-\mathrm{sec}$ delays. A $20-\mathrm{sec}$ intertrial interval was used for all delay conditions. Testing procedures were similar for Set 2 except that only the 120- and 600-sec delays were used.

Lists. For Set 1 only, a "lists" version of DNMS was conducted. For this version of the task, the number of objects presented for familiarization on the sample trial prior to the recognition trial was increased, in stages, from 1 to 3 , then to 5 , and finally to 10 objects, presented serially (lists of 3,5, and 10 items). Then, on the recognition trials, in the same order, each of the sample items was paired with a novel object. The monkeys were first given 30 trials in one session on the basic 10-sec delay condition with a single object. On the next day, lists of 1 were administered. On the following day, three different objects were presented serially over the baited central food well at $10-\mathrm{sec}$ intervals. Twenty seconds after the presentation of the last item, the first of the three sample objects was presented paired with a novel object, and, at 10 -sec intervals, the other sample objects were successively presented with other novel objects in the same order in which the list of sample items had been first presented. Ten different lists of three were presented in one session of 30 trials. Similarly, the same procedure was used by presenting six lists of five objects on Day 3 and three lists of 10 sample objects on Day 4 . The 4 days constituted one block, and a total of two blocks were given, so that each monkey received a total of 60 trials with each of the list lengths. The pool of 400 objects that had been used for both the acquisition portion and the delay portion of the task was also used for the list portion of the task. The objects were recombined every 180 trials in order to ensure that each presentation was trial unique (i.e., the pairing of novel and familiar objects had not been seen before). The delays between the initial presentation and the recognition presentation of a given item, including the time taken to respond on each of the sample presentation trials, were approximately $10 \mathrm{sec}$ for list lengths of $1,50 \mathrm{sec}$ for list lengths of 3, $75 \mathrm{sec}$ for list lengths of 5, and $140 \mathrm{sec}$ for list lengths of 10 items.

Retraining on the DNMS principle. All monkeys were brought back to criterion levels of performance on the 10-sec delay condition of the DNMS task before being administered the DRST.

DRST. The DRST is a short-term memory test that was designed to investigate recognition memory in monkeys following bilateral removal of the hippocampus (Moss, 1983; Rehbein, 1985). It requires the subject to identify, trial by trial, the new stimulus within an increasing array of serially presented stimuli. The task was administered using different classes of stimulus material in order to help characterize recognition memory deficits across several stimulus domains (see Figure 1). In the present study, the DRST was administered using the spatial, color, and object conditions. For the spatial condition, 15 identical plain brown disks, $6 \mathrm{~cm}$ in diameter, were used as stimuli. A disk was placed over one of the 18 wells, which was baited. The screen was raised, and the monkey was allowed to displace the disk to obtain the reward. The screen was lowered, and a second disk was placed on the board with the well it covered baited; the first disk was returned to its original position over the now-unbaited well. After $10 \mathrm{sec}$, the screen was raised, and the monkey was required to displace the new disk in order to obtain the reward. Each successive correct response was followed by the addition of a new disk until the monkey made an error (i.e., chose one of the previously chosen disks). With the occurrence of the first error, the trial was terminated, and the number of disks on the test tray minus one constituted the recognition span score for that trial (i.e., number of correct responses). Ten such trials were presented each day, 7 or 8 of which 


\section{Spatial}

Condition

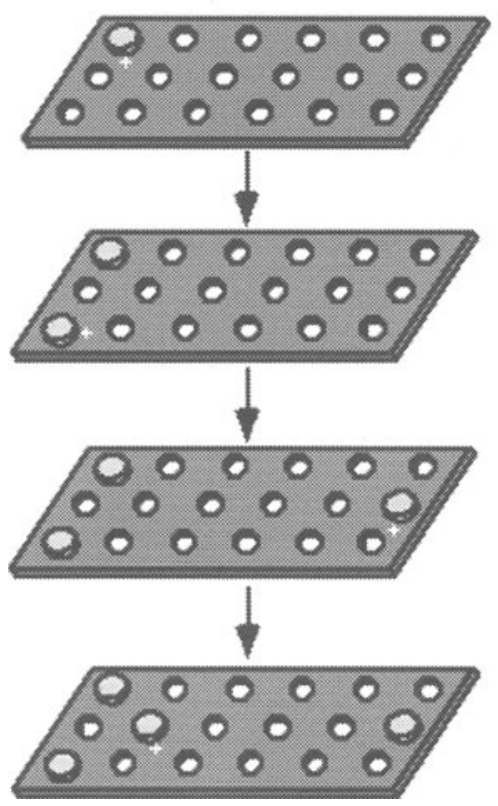

Color Condition
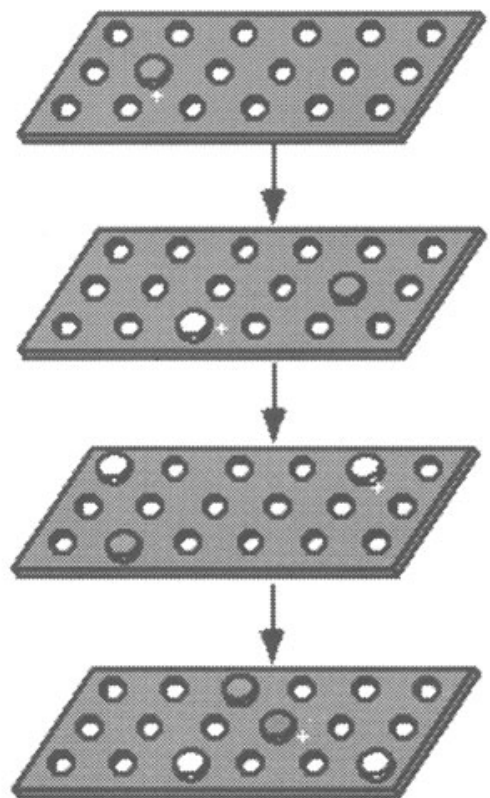

Object Condition
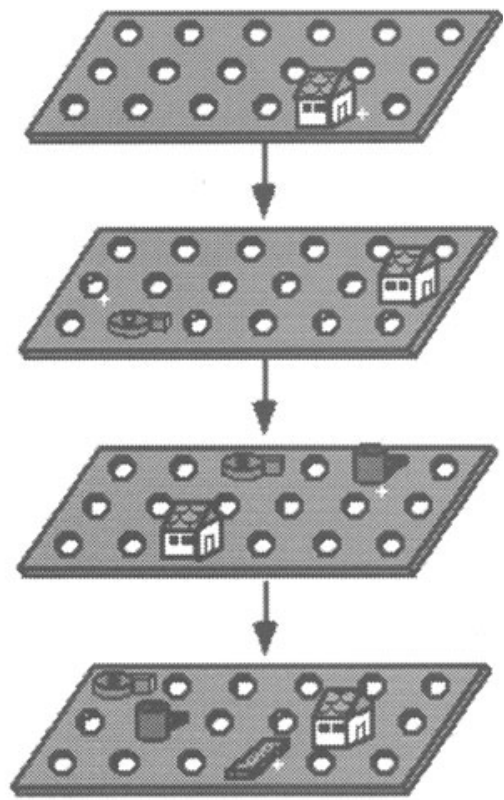

Figure 1. Representation of the testing procedures for the spatial, color, and object conditions of the delayed recognition span task.

were unique sequences of stimuli and 2 or 3 of which were the same single sequence that was repeatedly represented to the monkey. This continued for 10 consecutive days ( 100 trials, 75 unique and 25 repeated). For the repeated trials, one spatial sequence was re-presented to the monkey throughout the spatial condition of the task (i.e., was repeated two or three times each and every day).

The color condition of this task was administered in the same fashion as the spatial condition with two exceptions. First, the stimuli were 15 identically shaped but different colored disks, $6 \mathrm{~cm}$ in diameter. Second, within each trial, the position of all previously presented stimuli were changed in a pseudorandom fashion so that the monkey had to identify the new stimulus on the basis of visual cues without the use of spatial cues. For the repeated trials, one color sequence with the same spatial locations was re-presented to the monkey throughout this condition of the task.

The object condition of this task was administered in the same fashion as the color condition with the following exception: The stimuli for all but the repeated trials were drawn from a pool of 400 junk objects. As on the color condition, within each trial, the position of the previously correct stimuli were changed in a pseudorandom fashion so that the monkey had to identify the new stimulus on the basis of visual cues without the use of spatial cues. For the repeated trials, a set of 15 objects was used with one sequence of presentations so that the sequence of objects, as well as the sequence of positions, was the same on all these trials.

In order to determine whether there was a significant effect of practice over the three stimulus conditions after testing on all three DRST conditions was completed, the spatial condition of the DRST was readministered to a subset of 4 young adult animals (AM52, AM56, AM34, and AM37). This spatial task was administered for 10 trials a day for 2 consecutive days, for a total of 20 trials.

Acquisition scores on the DNMS task were analyzed statistically in terms of both trials and errors to criterion by parametric one-way analyses of variance (ANOVAs). Analyses for the acquisition task were based on the number of trials and errors committed before learning criterion was reached. Performance scores for both delay conditions and lists were analyzed by separate two-way, repeated measures ANOVAs, with age group as a between-subjects factor and delays or list lengths as a within-subjects factor. In order to avoid the risk of finding spurious interactions, only the delay conditions (excluding the 10-sec delay condition) were included in the analyses. These analyses were followed, when appropriate, by a posteriori comparisons of simple main effects (Hayes, 1988; Kirk, 1982). Analyses of the data obtained from the delay and list conditions were based on percentages of correct responses for each condition.

The performance scores obtained by the individual monkeys on the three conditions of the DRST were analyzed in two ways. First, the overall performance on each condition of the DRST was assessed separately by parametric one-way ANOVAs. Second, the performance within each of the three DRST conditions was assessed by two-way ANOVAs, with age group as a between-subjects factor and type of sequence as a within-subjects factor. These were followed, when appropriate, by a posteriori tests of simple main effects (Hayes, 1988; Kirk, 1982). All a posteriori comparisons were assessed according to methods to provide experimentwise control for Type I errors (Petrinovich \& Hardyck, 1969).

\section{RESULTS}

\section{DNMS Acquisition}

Individual monkey performance, in terms of trials and errors to criterion, is listed in Table 2 for the acquisition phase of the DNMS task. The young adult monkeys learned the task readily in $30-400$ trials, with a mean of 53.4 errors. The scores for the early senescent monkeys ranged from 60 to 1,660 trials, with a mean of $123.2 \mathrm{er}-$ rors. Between-group comparisons showed a trend that did not reach the level of statistical significance $(p s>.05)$ 
Table 2

Acquisition Scores for DNMS Task

\begin{tabular}{|c|c|c|}
\hline Monkey & Trials & Errors \\
\hline \multicolumn{3}{|c|}{ Young Adult } \\
\hline AM22 & 220 & 60 \\
\hline AM35 & 140 & 48 \\
\hline AM76 & 220 & 58 \\
\hline AM32 & 280 & 56 \\
\hline AM52 & 300 & 62 \\
\hline AM47 & 80 & 21 \\
\hline AM56 & 200 & 52 \\
\hline AM57 & 400 & 96 \\
\hline AM33 & 240 & 91 \\
\hline AM34 & 210 & 60 \\
\hline AM39 & 200 & 44 \\
\hline AM66 & 30 & 7 \\
\hline AM37 & 180 & 35 \\
\hline AM49 & 210 & 57 \\
\hline$M$ & 207.8 & 53.4 \\
\hline \multicolumn{3}{|c|}{ Early Senescent } \\
\hline AM24 & 360 & 92 \\
\hline AM38 & 560 & 173 \\
\hline AM48 & 480 & 132 \\
\hline AM50 & 1,660 & 541 \\
\hline AM63 & 320 & 43 \\
\hline AM64 & 340 & 77 \\
\hline AM67 & 60 & 10 \\
\hline AM68 & 240 & 60 \\
\hline AM31 & 274 & 60 \\
\hline AM26 & 260 & 83 \\
\hline AM30 & 267 & 96 \\
\hline AM19 & 280 & 111 \\
\hline$M$ & 425.1 & 123.2 \\
\hline
\end{tabular}

Note- Order of monkeys corresponds to that shown in Table 1.

between the two groups either in terms of trials $[F(1,24)=$ $3.78, p=.064]$ or in terms of errors $[F(1,24)=3.48, p=$ $.07]$ to criterion.

\section{DNMS Delays of 30, 60, 120, and $300 \mathrm{sec}$}

The performance of the monkeys on the multipledelay condition of the DNMS task is illustrated in Figure 2. Analysis of the data revealed an overall significant effect of age $[F(1,9)=18.4, p=.002]$ and a trend toward a significant age $\times$ delay interaction $[F(3,27)=2.42, p=$ $.088]$. A posteriori comparisons revealed that the performance of the two groups did not differ significantly ( $p s>$ .05 ) at the 30 -sec delay interval. However, as the delays increased, the performance of the monkeys in the early senescent group became significantly worse than that of the young adult monkeys [60 sec, $F(1,36)=6.43, p<$ $.025 ; 120 \mathrm{sec}, F(1,36)=11.098, p<.005 ;$ and $300 \mathrm{sec}$, $F(1,36)=16.87, p<.001]$. The diminished group performance of the early senescent monkeys was not characteristic of all the monkeys in the group since a subset of monkeys (i.e., AM24 and AM48) performed as efficiently as the young adult monkeys on at least one of the three longest delay conditions.

The performance of both groups of monkeys was affected by the increased delays $[F(3,27)=3.6, p<.05]$, with a mean percentage correct for the young and early senescent groups declining from $90.7 \%$ and $90.2 \%$ at the 10 -sec delay to $89.6 \%$ and $75.7 \%$ at the $300-\mathrm{sec}$ delay, respectively.

\section{DNMS Delays of 120 and $600 \mathrm{sec}$}

The performance of the monkeys on the long-delay conditions of the DNMS task is illustrated in Figure 2. Analysis of the data revealed an overall significant effect of age $[F(1,13)=10.92, p=.0057]$ but failed to show an age $\times$ delayed interaction $[F(1,13)=2.52, p=.14]$. A posteriori comparisons between the performance of the two groups at each delay were made with separate oneway ANOVAs, using controlled significance levels (i.e., criterion $p=.05 /$ number of tests; in our case, criterion $p=.025$ ). These analyses revealed that, as the delays increased, the performance of the monkeys in the early senescent group became significantly worse $[120 \mathrm{sec}$, $F(1,13)=6.45, p<.025 ; 600 \mathrm{sec}, F(1,13)=17.7, p<$ $.001]$ than that of the young adult monkeys. The performance of both groups of monkeys was significantly affected by the increased delays $[F(2,26)=39.34, p<$ $.0001]$, with a mean percentage correct for the young and early senescent groups declining from $90.4 \%$ and $90.5 \%$ at the $10-\mathrm{sec}$ delay to $81.4 \%$ and $67.0 \%$ at the $600-\mathrm{sec}$ delay, respectively.

\section{DNMS Lists}

The performance of the monkeys on the list condition of the DNMS task is illustrated in Figure 2. Analysis of the data revealed an overall significant effect of age $[F(1,9)=17.845, p=.0022]$ and a significant age $\times$ list length interaction $[F(3,27)=5.22, p=.005]$. A posteriori comparisons revealed that the performance of the two groups did not differ significantly $(p>.05)$ in the list of 1 condition (which is simply the basic DNMS task). However, as the list length increased, the performance of the monkeys in the early senescent group became significantly impaired with respect to the performance of the young adult monkeys [lists of $3, F(1,36)=7.97, p<.01$; lists of $5, F(1,36)=18.71, p<.001$; lists of $10, F(1,36)=$ $17.08, p<.001]$. The performance of both groups of monkeys was significantly affected by the increased list length $[F(3,27)=34.15, p<.0001]$, with a mean percentage correct for the young and early senescent groups declining from $90.3 \%$ and $90.0 \%$ on the list of 1 condition to $78.8 \%$ and $66.3 \%$ on the list of 10 condition, respectively.

\section{DRST Spatial Condition}

The overall individual performance of the monkeys on the DRST spatial condition is given in Table 3. Group mean performance on each type of sequence is illustrated in Figure 3. Analysis of the data revealed an overall significant effect of age $[F(1,24)=19.33, p=.0002]$ and a significant age $\times$ sequence interaction $[F(1,24)=4.62$, $p=.004]$. A posteriori comparisons revealed that the per- 

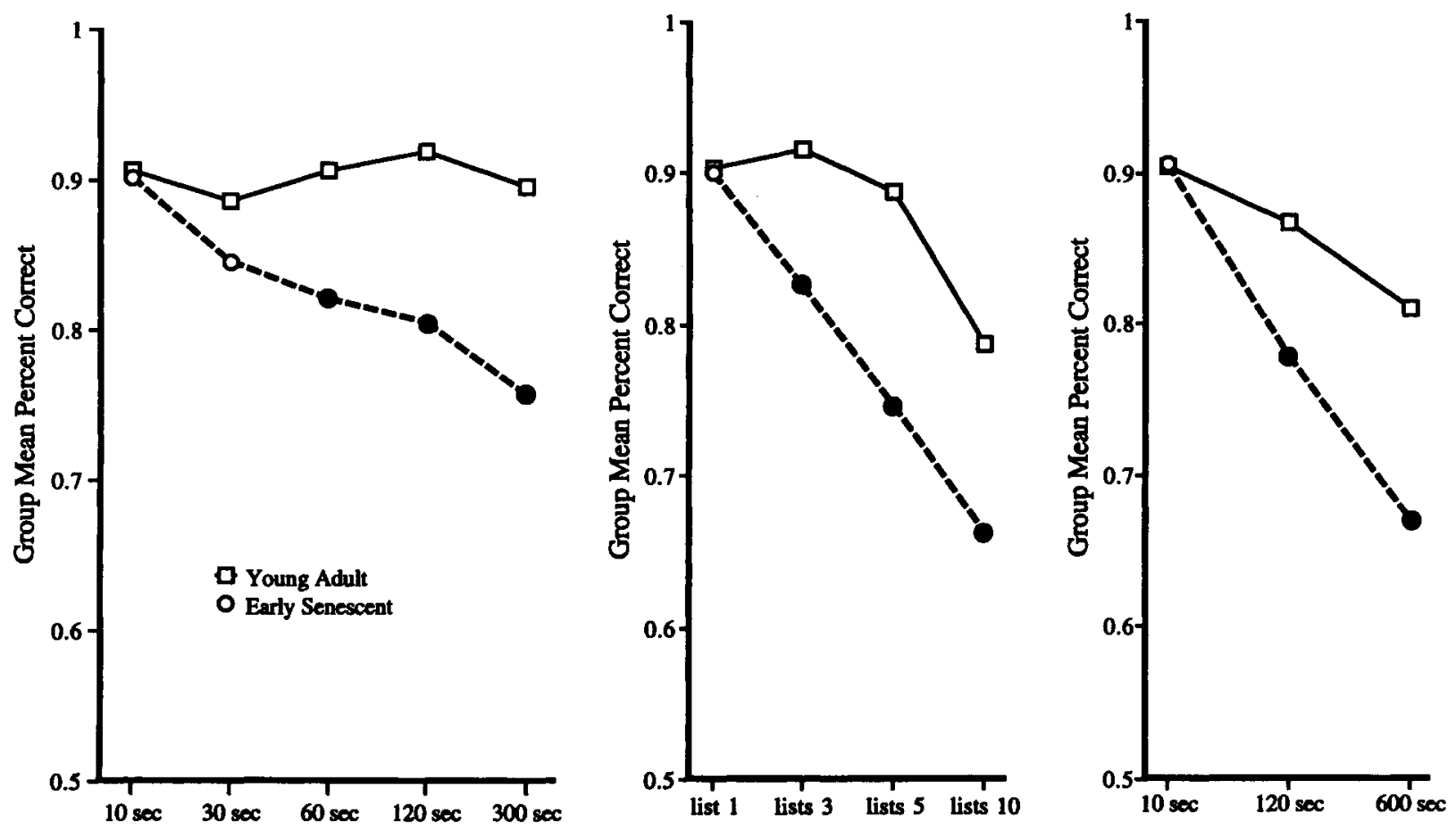

Figure 2. Illustration of the mean group performance on the delay and list conditions of the delayed nonmatching-to-sample task. Large filled circles indicate a significant $(p \mathrm{~s}<.05)$ decline in the performance of the early senescent group with respect to the performance of the young adult group.

formance of the two groups differed on both the repeated $[F(1,48)=22.92, p<.001]$ and the nonrepeated $[F(1,48)=$ $4.59, p<.05]$ sequences.

The performance of both groups was significantly affected by the type of sequence $[F(1,24)=44.89, p<.001]$, with both groups showing an increased span length. For the young adults, DRST performance increased from an average of 2.32 on the nonrepeated sequences to an average of 3.27 on the repeated sequences. For the early senescent group, performance increased from an average of 1.95 on the nonrepeated sequences to an average of 2.44 on the repeated sequences.

\section{DRST Color Condition}

The overall individual performance of the monkeys on the DRST color condition is given in Table 3. Group mean performance on each type of sequence is illustrated in Figure 3. Analysis of the data failed to reveal either an overall significant effect of age $[F(1,21)=3.19, p=.089]$ or an age $\times$ sequence interaction $[F(1,21)=0.68, p=.42]$.

The performance of both groups was significantly affected by the type of sequence $[F(1,21)=36.61, p<$ $.0001]$, with both groups showing an increased span length from an average of 3.12 on the nonrepeated sequences for the young adult group to an average of 4.02 for this group on the repeated sequences and from an average of 2.6 on the nonrepeated sequences for the early senescent group to an average of 3.3 on the repeated sequences.

\section{DRST Object Condition}

The overall individual performance of the monkeys on the DRST object condition is given in Table 3. Group mean performance on each type of sequence is illustrated in Figure 3. Analysis of the data revealed an overall significant effect of age $[F(1,14)=19.22, p=.0006]$ but no age $\times$ sequence interaction $[F(1,14)=1.77, p=.2]$. A posteriori comparisons between the performance of the two groups on each sequence type were made with separate one-way ANOVAs using controlled significance levels (i.e., criterion $p=.05 /$ number of tests; in our case, criterion $p=.025$ ). These analyses revealed a significant effect of age on both the repeated $[F(1,14)=22.64, p=$ $.0003]$ and the nonrepeated $[F(1,14)=12.53, p=.0033]$ sequences. Interestingly, the performance of both the young adult monkeys and the early senescent monkeys, as groups, were not significantly affected by the type of sequence $[F(1,14)=2.24, p=.16]$ on the object condition.

\section{DRST Spatial Retest}

In the 4 young adults (AM52, AM56, AM34, and AM37) that were readministered the spatial DRST, the spans ranged from 2.35 to $3.07(M=2.70)$, compared with initial spatial spans ranging from 2.85 to $3.13(M=$ 3.0). A matched sample version of Student's $t$ test did not reveal a statistically significant difference between the initial spatial spans and the readministered spatial span for these monkeys $(p>.10)$. 
Table 3

Overall Performance on the Delayed Recognition Span Task

\begin{tabular}{|c|c|c|c|}
\hline \multirow[b]{2}{*}{ Monkey } & \multicolumn{3}{|c|}{ Condition } \\
\hline & Spatial & Color & Object \\
\hline \multicolumn{4}{|c|}{ Young Adult } \\
\hline AM22 & 2.53 & 4.62 & \\
\hline AM35 & 2.62 & 4.19 & \\
\hline AM76 & 2.35 & 2.32 & 5.28 \\
\hline AM32 & 2.39 & 4.45 & \\
\hline AM52 & 2.85 & 3.36 & 5.32 \\
\hline AM47 & 2.23 & 2.59 & 3.58 \\
\hline AM56 & 3.14 & 3.94 & 4.83 \\
\hline AM57 & 2.20 & & 3.90 \\
\hline AM33 & 2.52 & 3.61 & 3.91 \\
\hline AM34 & 3.13 & 3.45 & 4.87 \\
\hline AM39 & 2.48 & 3.16 & 4.25 \\
\hline AM66 & 2.24 & 2.16 & 4.40 \\
\hline AM37 & 2.89 & 3.21 & 4.67 \\
\hline AM49 & 2.36 & 2.74 & \\
\hline$M$ & 2.57 & 3.37 & 4.50 \\
\hline \multicolumn{4}{|c|}{ Early Senescent } \\
\hline AM24 & 2.56 & 3.48 & \\
\hline AM38 & 1.94 & 2.28 & \\
\hline AM48 & 2.20 & 3.55 & \\
\hline AM50 & 1.86 & & 2.07 \\
\hline AM63 & 2.00 & 2.51 & 4.16 \\
\hline AM64 & 2.26 & 2.28 & 3.79 \\
\hline AM67 & 2.06 & 2.31 & 2.44 \\
\hline AM68 & 2.01 & 2.54 & 3.42 \\
\hline AM31 & 1.65 & & 2.43 \\
\hline AM26 & 1.98 & 2.27 & \\
\hline AM30 & 1.94 & 2.38 & \\
\hline AM19 & 2.34 & 4.42 & \\
\hline$M$ & 2.07 & 2.80 & 3.05 \\
\hline
\end{tabular}

Note--Order of monkeys corresponds to that shown in Table 1.

\section{Intertask Performance}

In order to assess the relationship of performance within components of the DNMS and DRST, as well as that across the two tasks, we conducted two separate analyses using the scores for the DNMS basic task, DNMS 2min delay condition, DRST spatial condition, and DRST color condition. First, a correlational analysis (Pearson product moment) revealed, perhaps not surprisingly, significant linear relationships between the acquisition and the 2-min delay conditions of the DNMS as well as between the spatial and color conditions of the DRST (spatial and color conditions) ( $p$ s $<.01$, two-tailed). Of interest, but not intuitively clear, a significant but weaker correlation was found between performance on the 2-min delay condition and performance on the spatial condition of the DRST ( $p<.05$, two-tailed). Second, we performed a principle components analysis with five measures (age, DNMS basic task errors to criterion, DNMS 2-min delay, spatial DRST, and color DRST) that yielded five eigenvalues and six corresponding eigenvectors, each representing a series of loadings or weights for the original variables. The first three components in our analysis accounted for $87 \%$ of the total variance, with the first component correlating best with age $(r=.544)$ and spatial DRST $(r=-.521)$ together accounting for $52.5 \%$ of the total variance. The second component correlated best with DNMS errors to criterion $(r=.753)$ and color DRST $(r=$ $.606)$ and accounted for $22 \%$ of the variance. The third component correlated best with DNMS 2-min delay ( $r=$ -.850 ) and accounted for $12.5 \%$ of the variance.

\section{DISCUSSION}

The principle findings of this study were the following: (1) One third of the early senescent monkeys achieved learning scores on the DNMS task that were higher that those in the young adult group. However, as a group, their performance was not significantly different from that of young adult monkeys. (2) In contrast, the group of early senescent monkeys was significantly impaired relative to the group of young adult monkeys on delays of 60 , 120,300 , and $600 \mathrm{sec}$ and with list lengths of 3,5, and 10 (i.e., on tasks that required memory to span longer intervals and/or to hold more information over longer intervals). (3) The early senescent monkeys achieved a significantly lower mean recognition span than did the young adult monkeys on the spatial and object conditions, but not the color condition of the DRST. (4) Both the young adult monkeys and the early senescent monkeys benefited from the repeated presentation of a sequence for the spatial and color, but not for the object conditions of the DRST.

The lack of impairment as a group by the early senescent monkeys on the acquisition of DNMS is consistent with findings from an earlier study (Presty et al., 1987). These investigators assessed the performance of a group of monkeys ranging in age from 20 to 24 years (Group III) and reported no significant impairment on acquisition of DNMS, with 4 of the 6 monkeys in the group obtaining trial and error scores that were comparable to those within the two younger groups of monkeys in the study. In the present study, 8 of 12 monkeys in the early senescent group obtained trial and error scores that were within the range of that obtained by the young adult group, a percentage that is equivalent to that seen in the study by Presty et al. (1987).

It should be noted that the performance of 1 monkey, AM50, contributed significantly to the variance in the data, because this monkey performed extremely poorly. In consideration of the status of this monkey as a possible "outlier," we carefully reviewed the medical and social history along with necropsy and neuropathological results and were not able to identify any unusual or atypical findings. Nonetheless, if we exclude the data from this monkey, a statistically significant difference emerges between the young adult monkeys and the early senescent monkeys in terms of both trials and errors to criterion on the basic task of the DNMS task. Indeed, this feature of the data may point to the dichotomous nature of the performance in the early senescent group. Eight out of 12 fell within the range of the young adult monkeys (see Table 2). The remaining 4 (AM38, AM48, AM50, and AM19) obtained error scores that were beyond the range of the 

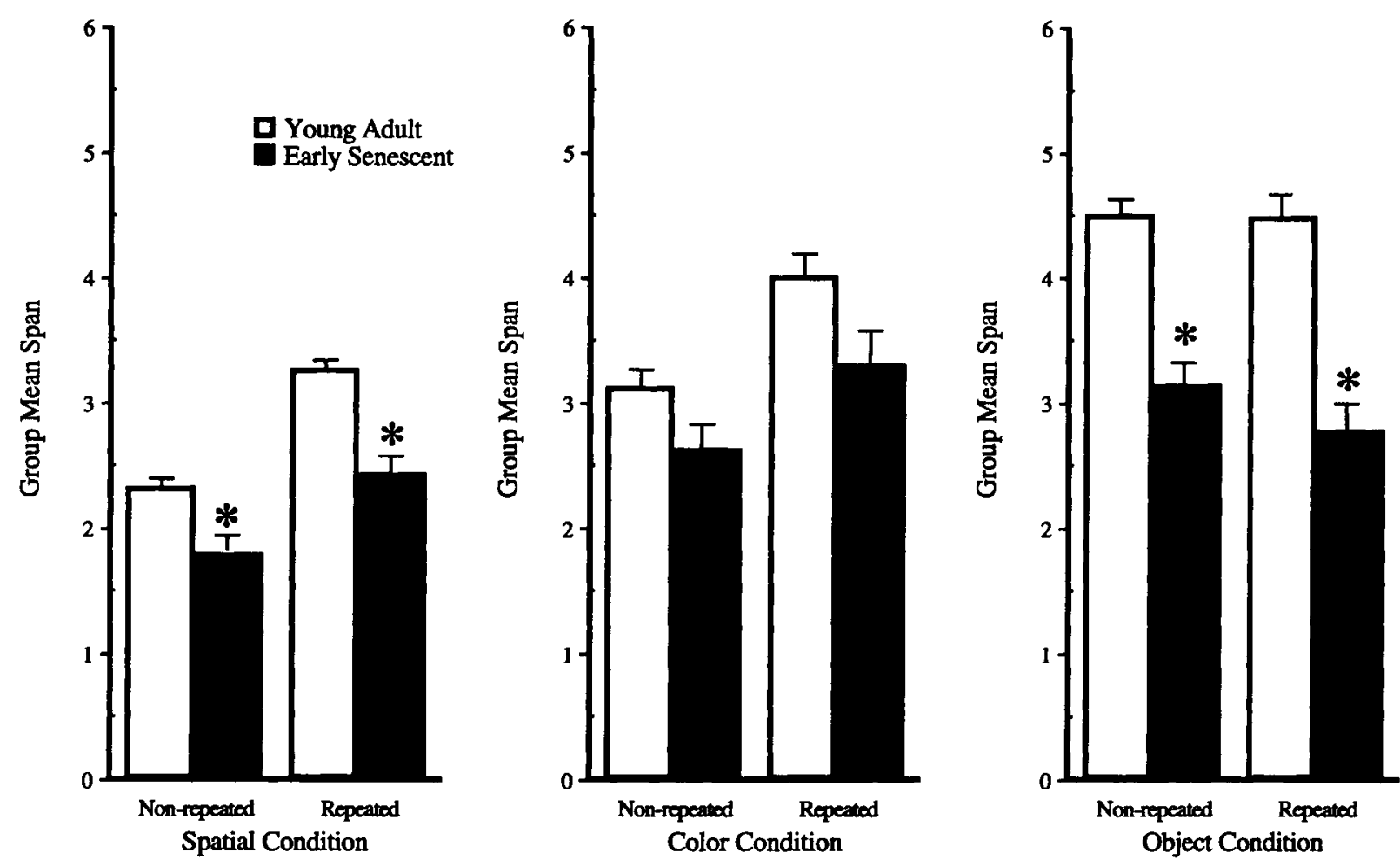

Figure 3. Illustration of the mean group performance on the repeated and nonrepeated sequences of the spatial, color, and object conditions of the delayed recognition span task. Asterisks indicate a significant $(p s<.05)$ impairment in the performance of the early senescent group with respect to the performance of the young adult group.

young adult group. This pattern of findings suggests that cognitive decline may be quite marked in some monkeys of early senescent age. It also raises the possibility that those performing in the normal range may emerge as the "successfully" aged monkeys later in life, whereas the impaired monkeys may go on to become "unsuccessfully" aged monkeys. Indeed, among the 4 most severely impaired monkeys, it is notable that 1 (AM38) was only 19 years of age, and 2 of them (AM48 and AM50) were only 20 years of age at the time of testing. Together with earlier findings from Bartus and colleagues (Bartus, 1979; Bartus \& Dean, 1979; Bartus, Dean, \& Fleming, 1979; Bartus et al., 1978), who demonstrated that rhesus monkeys estimated to be in the early senescent range are impaired on tasks of reversal learning and delayed response, these data would support the view that learning and memory function may evidence decline beginning in the late teens for monkeys, a period equivalent to the late $40 \mathrm{~s}$ for humans.

In contrast to the acquisition of DNMS, the monkeys in the early senescent group showed a significant impairment on the performance condition of the DNMS with delays greater than $30 \mathrm{sec}$ and list lengths greater than 1 . At first glance, this is at variance with the study by Presty et al. (1987), who found a significant overall age effect on a combined performance measure consisting of three de- lays (30,60, and $120 \mathrm{sec})$ and three list lengths $(3,5$, and $10)$, but a posteriori paired comparison analyses in their study did not show a significant impairment in the group of early senescent monkeys. It is plausible that the finding of a significant impairment by the early senescent monkeys in the present study was related to the increased demands of the task by use of two additional long delays ( 300 and $600 \mathrm{sec}$ ). Indeed, the early senescent monkeys in the present study evidenced a steep decline in accuracy of performance from criterion levels and delays of up to $60 \mathrm{sec}$ to delays of $300 \mathrm{or} 600 \mathrm{sec}$. Taken together, the data from these two studies lead to the conclusion that the impairment on the performance conditions of the DNMS by early senescent monkeys is relatively mild and is evident only under conditions of increased memory demands.

Relative to the young adults, the early senescent monkeys were significantly impaired on the spatial component of the DRST. The mean span achieved by the early senescent monkeys was comparable to that of the monkeys of advanced age (i.e., 25-29 years of age) (Moss et al., 1997). Eight of the 12 monkeys obtained spans that were lower than that of any of the young adult monkeys, a proportion that was greater than that seen for the color and object conditions of the DRST. ${ }^{1}$

The lower mean span achieved by both young adult and aged monkeys on the spatial condition of the DRST, rel- 
ative to that in the color and object conditions, deserves comment. While it is likely that this difference is attributable to the greater difficulty in storing increasing amounts of spatial information relative to nonspatial information, another interpretation of these findings might be related to the fact that the color and object conditions were presented following the spatial condition and, hence, reflect the benefits of practice. We assessed the possible role of practice in this regard by readministering the spatial condition of the DRST to a subset of 4 young adult monkeys after they completed the color and object conditions. Their average span of 3.0 on initial testing was not statistically different from the span of 2.7 they achieved on the subsequent testing. This suggests that practice is not playing a role in the higher scores achieved on the nonspatial conditions of the task.

Some additional features of the spatial condition of the DRST task are worth considering in the context of spatial memory function. For this task, the number of stimulus positions are limited to the 18 test board wells. Over the course of a daily test session, and by the end of the task, the number of times a disk appears over any one of the positions is nearly equivalent across all 18 positions. Hence, the memory demand of the task shifts more from that based on familiarity, as is the case in trial-unique DNMS, to that based on the temporal order of the stimuli presented within a trial. In this regard, the spatial DRST shares in common some of the elements of the delayed response task, in which remembering temporal factors (the last stimulus baited) is key to successful performance of the task. Thus, it may not be of great surprise that, like delayed response (Arnsten \& Goldman-Rakic, 1985; Bachevalier et al., 1991; Bartus et al., 1978; Davis, Bennet, \& Weisenburger, 1982; Marriott \& Abelson, 1980; Medin \& Davis, 1974; Walker et al., 1988), the spatial condition of the DRST appears to be relatively sensitive to aging in the monkey. Indeed, this is supported by the principle components analysis, which revealed that performance on the spatial condition of the DRST was more strongly related to age than any of the other task performance measures.

The monkeys in the early senescent group also evidenced impairment relative to the young adults on the object condition of the recognition span task. The degradation in object memory span appears to continue with age, as suggested by findings in a related study (Moss, Killiany, Rosene, \& Herndon, 2000) in which monkeys in the oldest old range $(29+$ years) obtained a mean object span that was markedly lower than that found in the early senescent group in the present study.

In contrast to their performance on the spatial and object conditions of the DRST, the early senescent monkeys, as a group, were not significantly impaired on the color condition. This finding was somewhat surprising in view of the fact that early senescent monkeys were impaired in the other nonspatial span condition using three- dimensional random objects rather than colored disks. Despite the lack of a significant group difference, the mean color recognition span achieved by the early senescent group was $17 \%$ lower than that for the young adults. This suggests that the effect of age on color recognition, while present, may be relatively mild. Indeed, monkeys of more advanced age evidence a significant impairment in color span relative to young adults (Moss et al., 1997).

It is unclear why the degree of difficulty on nonspatial recognition span by early senescent monkeys would be related to the nature of the stimuli. One immediate explanation that comes to mind is that older monkeys may benefit by limiting the number of stimulus dimensions to be processed and recognized, as is the case with color stimuli. However, in view of the fact that aged monkeys have little difficulty learning object discrimination tasks (Lai, Moss, Killiany, Rosene, \& Herndon, 1995; Moss et al., 1988; Rapp, 1990), it is difficult to support this notion and, indeed, further investigation will be required to address this particular finding.

One other aspect of the DRST to be considered is the series of repeated trials embedded within each stimulus condition. Both the young adult monkeys and the early senescent monkeys achieved longer spans with repeated trials on the spatial and color conditions, but not on the object condition. While these findings suggest that early senescent monkeys, like young adults, can benefit from repetition, the effect may be limited. In view of the fact that all monkeys achieved their highest overall span on the object condition, it may be the case that their ability to improve performance with repetition may have reached asymptotic levels toward a maximum memory capacity. However, this notion can only be answered empirically with further study.

In summary, monkeys in the early senescent stage of aging, as a group, appear to present a dichotomous profile of preserved and impaired learning and memory function. Whereas most are as efficient in their acquisition of a nonmatching strategy as young adult monkeys, they are more likely to evidence impairment when required to retain information over long delays. Similarly, early senescent monkeys appear to have a more limited "span" for retaining serial information than do young adult monkeys, and this seems particularly true for the spatial stimulus domain.

The neurobiological basis for the age-related cognitive decline observed in aged monkeys, particularly with respect to memory function, has become an increasing focus of study in recent years. Structures or neural systems that have been implicated in these deficits, primarily as a result of lesion studies in nonhuman primates, include the medial temporal lobe/hippocampal system (Bachevalier \& Mishkin, 1986, 1989; Beason-Held, Rosene, Killiany, \& Moss, 1999; Goldman-Rakic \& Brown, 1981; Mishkin, 1978; Murray \& Mishkin, 1984, 1986; O'Boyle, Murray, \& Mishkin, 1993; Zola-Morgan \& Squire, 1985, 1986; 
Zola-Morgan, Squire, \& Amaral, 1989) and prefrontal cortices (Bachevalier \& Mishkin, 1986; Goldman-Rakic, 1987).

Monkeys with damage to structures within the hippocampal-temporal lobe limbic system have been shown to be impaired on the delay conditions of the DNMS task (Bachevalier \& Mishkin, 1986, 1989; Beason-Held et al., 1999; Goldman-Rakic, 1987; Meunier, Hadfield, Bachevalier, \& Murray, 1996; Mishkin, 1978; Murray \& Mishkin, 1984, 1986; Zola-Morgan \& Squire, 1985, 1986; Zola-Morgan, Squire, \& Amaral, 1989; Zola-Morgan, Squire, Clower, \& Rempel, 1993) as well as on the recognition span task (Beason-Held et al., in press). Indeed, it is tempting to consider that the early stages of aging reflect compromise of temporal lobe limbic system function and, specifically, of the hippocampus, a notion that has been advanced by investigators in the field (Moss et al., 1988; Rapp \& Amaral, 1991). Detracting from this argument is the fact that, at least in the monkey, the hippocampal formation does not undergo significant neuronal loss with age (Amaral, 1993; Rosene, 1993), although West (1993) has reported a loss of neurons in subfield CA4 and the subiculum in the hippocampus of normal aged humans. We have also examined the dentate gyrus in aged monkeys and found that there is no significant evidence of synaptic loss (Tigges, Herndon, \& Rosene, 1996). While changes in other domains such as dendrites, receptors or axons, and myelin may be present, it seems unlikely that the present observations could be accounted for by hippocampal dysfunction alone, given the relative preservation of neurons and synapses.

The growing body of evidence of impairment on tasks of spatial memory and those requiring retention of temporal order in aged monkeys (Rapp \& Amaral, 1991) implicates the prefrontal cortex as another major cortical locus for age-related neurobiological impairment, a view advanced earlier by Bartus and his colleagues (Bartus, 1979; Bartus \& Dean, 1979). Adding support to this notion are findings that aged monkeys are impaired on tasks of executive system function (Bachevalier, 1993; Lai et al., 1995; Moore, Killiany, Rosene, \& Moss, 1998), a cognitive domain that includes abilities likely mediated by prefrontal cortical areas (Bachevalier \& Mishkin, 1986; Goldman-Rakic, 1987; Goldman-Rakic \& Brown, 1981). However, any direct or selective involvement of area 46 with age has not yet been established. Neurons in area 46 of prefrontal cortex (Peters, Leahu, Moss, \& McNally, 1994) do not undergo cell loss in monkeys of even advanced age (25-29 years), although the white matter in this region has been shown to undergo alteration (Peters et al., 1994). It is also of interest that aged monkeys, including those of early age, evidence marked cell loss in the nucleus raphe dorsalis and nucleus centralis superior of the brainstem (Kemper, 1993; Kemper, Moss, Rosene, \& Killiany, 1997). Both nuclei are serotonergic and have sizable projections to prefrontal cortical regions. Reduction in endogenous concentrations of dopamine have been reported in the prefrontal cortex (Goldman-Rakic \&
Brown, 1981), and loss of serotonin binding has also been reported in the frontal cortex and hippocampus with age (Marcusson, Morgan, Winblad, \& Finch, 1984). Perhaps the most direct evidence of involvement of area 46 comes from a recent study from our group showing a reduction of synapses and thinning of Layer I in aged monkeys (Peters et al., 1997).

Of final note, neuritic plaques have been identified in aged monkeys (Struble, Price, Cork, \& Price, 1985), with a predilection for the prefrontal and temporal areas when they do appear. Although related to age, their presence and distribution do not appear to be related to cognitive function (Sloane, Rosene, Moss, Kemper, \& Abraham, 1997).

In conclusion, the results of the present investigation add to the growing body of evidence that rhesus monkeys undergo a decline in memory function at a relatively early age, a finding that is in parallel with observations made in normal human aging (Albert \& Moss, 1999). However, the neurobiological basis for this change has yet to be worked out, though initial findings from anatomical studies raise the possibility that the bases for this decline may be related to a deterioration in the efficiency and quality of information processing due to alterations and/or loss in myelin linking cortical association and limbic regions (Peters et al., 1994; Rosene et al., 2000), rather than to the long-standing concept of frank cortical neuronal cell loss (Peters, Morrison, Rosene, \& Hyman, 1998).

\section{REFERENCES}

AgGleton, J. P., \& Mishrin, M. (1983). Visual recognition impairment following medial thalamic lesions in monkeys. Neuropsychologia, 21, 189-197.

Albert, M. S., \& Moss, M. B. (1984). The assessment of memory disorders in patients with Alzheimer's disease. In L. Squire \& N. Butters (Eds.), Neuropsychology of memory (pp. 236-246). New York: Guilford.

Albert, M. S., \& Moss, M. B. (1999). Profiles of cognition in normal aging. In A. Peters \& J. Morrison (Eds.), Cerebal cortex (Vol. 13, pp. 1-20). New York: Plenum.

Alverez, P., Zola-Morgan, S., \& SQuire, L. R. (1995). Damage limited to the hippocampal region produces long-lasting memory impairment in monkeys. Journal of Neuroscience, 15, 3796-3807.

AMARAL, D. G. (1993). Morphological analyses of the brains of behaviorally characterized aged nonhuman primates. Neurobiology of Aging, 14, 671-672.

ARnsten, A. F. T., \& Goldman-Rakic, P. S. (1985). A-2 adrenergic mechanisms in prefrontal cortex associated with cognitive decline in aged nonhuman primates. Science, 230, 1273-1276.

Arnsten, A. F. T., \& Goldman-RakiC, P. S. (1990). Analysis of a-2 adrenergic agonist effects on the delayed nonmatch-to-sample performance of aged rhesus monkeys. Neurobiology of Aging, 11, 583-590.

BACHEVALIER, J. (1993). Behavioral changes in aged rhesus monkeys. Neurobiology of Aging, 14, 619-621.

Bachevalier, J., Landis, L. C., Walker, M., Brickson, M., Mishin, M., Price, D. L., \& CoRK, L. C. (1991). Aged monkeys exhibit behavioral deficits indicative of widespread cerebral dysfunction. Neurobiology of Aging, 12, 99-111.

BaChevalier, J., \& Mishkin, M. (1986). Visual recognition impairment follows ventromedial but not dorsolateral prefrontal lesions in monkeys. Behavioral Brain Research, 20, 249-261.

Bachevalier, J., \& Mishkin, M. (1989). Mnemonic and neuropatho- 
logical effects of occluding the posterior cerebral artery in macaca mulatta. Neuropsychologia, 27, 83-105.

BARTUS, R. T. (1979). Effects of aging on visual memory, sensory processing and discrimination learning in a nonhuman primate. In J. M. Ordy \& K. Brizzee (Eds.), Sensory systems and communication in the elderly (pp. 137-145). New York: Raven.

BarTus, R. T., \& DEAN, R. L, III (1979). Recent memory in aged nonhuman primates: Hypersensitivity to visual interference during retention. Experimental Aging Research, 5, 385-400.

Bartus, R. T., DeAN, R. L., III, \& Fleming, D. L. (1979). Aging in the rhesus monkey: Effects on visual discrimination learning and reversal learning. Journal of Gerontology, 34, 209-219.

Bartus, J. M., Fleming, D., \& Johnson, H. R. (1978). Aging in the rhesus monkey: Debilitating effects on short-term memory. Journal of Gerontology, 34, 209-219.

Beason-Held, L., Rosene, D. L., Killiany, R. J., \& Moss, M. B (1999). Memory deficits associated with ibotenic acid lesions of the hippocampal formation in rhesus monkeys. Hippocampus, 9, 562574.

BlACKFORD, R. C., \& LA RUE, A. (1989). Criteria for diagnosing age associated memory impairment: Proposed improvements from the field. Developmental Neuropsychology, 5, 295-306.

Comparet, P., Darriet, D., \& JafFard, R. (1992). Demonstration of dissociation between frontal and temporal lesions in man on two versions of delayed nonmatching recognition tests used in monkeys. $C R$ Academy of Science, 314, 515-518

Crook, T., Bartus, R. T., Ferris, S. H., Whitehouse, P., Cohen, G. D., \& Gershon, S. (1986). Age associated memory impairment: Proposed diagnostic criteria and measures of clinical changeReport of a National Institute of Mental Health work group. Developmental Neuropsychology, 2, 261-276.

Davis, R. T., BenNet, C. L., \& Weisenburger, R. P. (1982). Repeated measurements of forgetting by rhesus monkeys (Macaca mulatta). Perceptual Motor Skills, 55, 703-709.

GaFFAN, D. (1974). Recognition impaired and association intact in the memory of monkeys after transection of the fornix. Journal of Comparative \& Physiological Psychology, 86, 1100-1 109.

Gellerman, L. W. (1933). Chance orders of alternating stimuli in visual discrimination experiments. Journal of General Psychology, 42, 207-208

Gilbert, J. G., \& Levee, R. F. (1971). Patterns of declining memory. Journal of Gerontology, 26, 70-75.

GoldMAN-RAKIC, P. S. (1987). Circuitry of primate prefrontal cortex and regulation of behavior by representational memory. Handbook of Physiology, 5, 373-417.

Goldman-Rakic, P. S., \& Brown, R. M. (1981). Regional changes in monoamines in cerebral cortex and subcortical structures of aging rhesus monkeys. Neuroscience, 6, 177-178.

HaRlow, H., \& Bromer, J. A. (1938). A test-apparatus for monkeys. Psychological Review, 19, 434-438.

HAyes, W. L. (1988). Statistics (4th ed.). New York: Holt, Rinehart \& Winston.

Inouye, S. K., Albert, M. S., Mohs, R., Sun, K., \& Berkman, L. F. (1993). Cognitive performance in a high-functioning communitydwelling elderly population. Journal of Gerontology, 48, 146-151.

KEMPER, T. L. (1993). The relationship of cerebral cortical changes to nuclei in the brainstem. Neurobiology of Aging, 14, 659-660.

Kemper, T. L., Moss, M. B., Rosene, D. L., \& Killiany, R. J. (1997). Age-related neuronal loss in the nucleus centralis superior of the rhesus monkey. Acta Neuropathologia, 94, 124-130.

KIRK, R. E. (1982). Experimental design: Procedures for the behavioral scientist (2nd ed.). Pacific Grove, CA: Brooks/Cole.

LaI, Z. C., Moss, M. B., Killiany, R. J., Rosene, D. L., \& Herndon, J. G. (1995). Executive system dysfunction in the aged monkey: Spatial and object reversal learning. Neurobiology of Aging, 16, 947-954

Lange, K. W., Robbins, T. W., Marsden, C. D., James, M., Owen, A. M., \& PAUL, G. M. (1992). L-dopa withdrawal in Parkinson's disease selectively impairs cognitive performance in tests sensitive to frontal lobe function. Psychopharmaçology, 107, 394-404.

LA RuE, A. (1982). Memory loss and aging: Distinguishing dementia from benign senescent forgetfulness and depressive pseudodementia. Psychiatric Clinics of North America, 5, 89-103.

Mahut, H., Moss, M. B., \& Zola-Morgan, S. (1982). Hippocampal resections impair associative learning and recognition memory in the monkey. Journal of Neuroscience, 2, 1214-1229.

Marcusson, J. O., Morgan, D. G., Winblad, B., \& Finch, C. E. (1984). Serotonin-2 binding sites in human frontal cortex and hippocampus. Selective loss of S-2A sites with age. Brain Research, 311, 51-56.

Marriott, J. G., \& Abelson, J. S. (1980). Age differences in shortterm memory of test-sophisticated thesus monkeys. Age, 3, 7-9.

Medin, D. L., \& Davis, R. T. (1974). Memory. In A. M. Shrier \& F. Stollmitz (Eds.), Behavior of non-human primates (pp. 1-47). New York: Academic Press.

Meunier, M., Hadfield, W., Bachevalier, J., \& Murray, E. A. (1996). Effects of rhinal cortex lesions combined with hippocampectomy on visual recognition memory in rhesus monkeys. Journal of Neurophysiology, 75, 1190-1205.

Mishkin, M. (1978). Memory in monkeys severely impaired by combined but not by separate removal of amygdala and hippocampus. $\mathrm{Na}$ ture, 273, 297-298.

Moore, T. L., Killiany, R. J., Rosene, D. L., \& Moss, M. B. (1998). Executive system dysfunction in the aged rhesus monkey using an analog of the Wisconsin Card Sorting Test. Society for Neuroscience Abstracts, 28, 1764.

Moss, M. B. (1983). Assessment of memory in amnesic and dementia patients: Adaptation of behavioral tests used with non-human primates. INS Bulletin, 12, 25.

Moss, M. B., Albert, M. S., Butters, N., \& Payne, M. (1986). Differential patterns of memory loss among patients with Alzheimer's disease, Huntington's disease, and alcoholic Korsakoff's syndrome. Archives of Neurology, 43, 239-246.

Moss, M. B., Killiany, R. J., Lai, Z. C., Rosene, D. L., \& Herndon, J. G. (1997). Recognition span in monkeys of advanced age. Neurobiology of Aging, 18, 13-19.

Moss, M. B., Killiany, R. J., Rosene, D. L., \& Herndon, J. G. (2000) Recognition memory in aged rhesus monkeys: Oldest of the old. Manuscript submitted for publication.

Moss, M. B., Rosene, D. L., \& Peters, A. (1988). Effects of aging on visual recognition memory in the rhesus monkey. Neurobiology of Aging, 9, 495-502.

MurRay, E. A., \& MishKIN, M. (1984). Severe tactual as well as visual memory deficits follow combined removal of the amygdala and hippocampus in monkeys. Journal of Neuroscience, 4, 2565-2580.

MURRAY, E. A., \& MishKIN, M. (1986). Visual recognition in monkeys following rhinal cortical ablations combined with either amygdalectomy or hippocampectomy. Journal of Neuroscience, 6, 1991-2003.

O'Boyle, V. J., Murray, E. A., \& Mishin, M. (1993). Effects of excitotoxic amygdalo-hippocampal lesions on visual recognition in rhesus monkeys. Society for Neuroscience Abstracts, 19, 438.

Peters, A., Leahu, D., Moss, M. B., \& McNally, K. J. (1994). The effects of aging on area 46 of the frontal cortex of the rhesus monkey. Cerebral Cortex, 6, 621-635.

Peters, A., Morrison, J. H., Rosene, D. L., \& Hyman, B. T. (1998). Are neurons lost from the primate cortex during normal aging? Cerebral Cortex, 8, 295-300.

Peters, A., Rosene, D. L., Moss, M. B., Kemper, T. L., Abraham, C. R., TigGes, J., \& ALBERT, M. S. (1997). Neurobiological bases of age related cognitive decline in the rhesus monkey. Journal of Neuropathology \& Experimental Neurology, 55, 861-874.

Petrinovich, L. F., \& HaRDYCK, C. D. (1969). Error rates for multiple comparison methods: Some evidence concerning the frequency of erroneous conclusions. Psychological Bulletin, 71, 43-54.

Presty, S. K., Bachevalier, J., Walker, L. C., Struble, R. G., Price, D. L., Mishkin, M., \& CoRK, L. C. (1987). Age differences in recognition memory of the rhesus monkey (Macaca mulatta). Neurobiology of Aging, 8, 435-440.

RAPP, P. R. (1990). Visual discrimination and reversal learning in the aged monkey (Macaca mulatta). Behavioral Neuroscience, 104, 876884.

RAPP, P. R., \& Amaral, D. G. (1989). Evidence for a task-dependent 
memory dysfunction in the aged monkey. Journal of Neuroscience, 9, 3568-3576.

RAPP, P. R., \& AMARAL, D. G. (1991). Recognition memory deficits in a subpopulation of aged monkeys resemble the effects of medial temporal lobe damage. Neurobiology of Aging, 12, 481-486.

REHBEIN, L. (1985). Long-term effects of early hippocampectomy in the monkey. Unpublished doctoral dissertation, Northeastern University.

ROSENE, D. L. (1993). Comparing age-related changes in the basal forebrain and hippocampus of the rhesus monkey. Neurobiology of Aging, 14, 669-670.

Rosene, D. L., Lai, Z. C., Killiany, R. J., Moss, M. B., Jolesz, F., \& ALBERT, M. S. (2000). Age-related loss of white matter with preservation of gray matter in the forebrain of the rhesus monkey-An MRI study. Manuscript submitted for publication.

Salmon, D. P., Granholm, E., McCullough, D., Butters, N., \& GRANT, I. (1989). Recognition memory span in mild and moderately demented patients with Alzheimer's disease. Journal of Clinical \& Experimental Neuropsychology, 4, 429-443.

Saunders, R. C., Murray, E. A., \& Mishkin, M. (1984). Further evidence that amygdala and hippocampus contribute equally to recognition memory. Neuropsychologia, 22, 758-796.

Sloane, J., Rosene, D. L., Moss, M. B., Kemper, T., \& Abraham, C. R. (1997). Lack of correlation between plaque burden and cognition in the aged monkey. Acta Neuropathologica, 94, 471-478.

Smith, G., Ivnik, R. J., Petersen, R. C., Malec, J. F., Kokmen, E., \& TANGALOS, E. (1991). Age-associated memory impairment diagnoses: Problems of reliability and concerns for terminology. Psychology \& Aging, 6, 551-558.

Squire, L., Zola-Morgan, S., \& Chen, K. S. (1988). Human amnesia and animal models of amnesia: Performance of amnesic patients on tests designed for the monkey. Behavioral Neuroscience, 102, 210 221.

Struble, R. G., Price, D. L., JR., Cork, L. C., \& Price, D. L. (1985). Senile plaques in cortex of aged normal monkeys. Brain Research, 361, 267-275.

Tigges, J., Gordon, T. P., McClure, H. M., Hall, E. C., \& Peters, A. (1988). Survival rate and life span of rhesus monkeys at the Yerkes Regional Primate Research Center. American Journal of Primatology, 15, 263-273.
Tigges, J., Herndon, J. G., \& Rosene, D. L. (1996). Preservation into old age of synaptic number and size in the supragranular layer of the dentate gyrus in rhesus monkeys. Acta Anatomica, 157, 63-72.

Walker, L. C., Kitt, C. A., Struble, R. G., Wagster, M. V., Price, D. L., \& CORK, L. C. (1988). The neural basis of memory decline in aged monkeys. Neurobiology of Aging, 9, 657-666.

WEST, M. J. (1993). Regionally specific loss of neurons in the aging human hippocampus. Neurobiology of Aging, 14, 287-293.

Zola-Morgan, S., \& SQuire, L. R. (1985). Medial temporal lesions in monkeys impair memory on a variety of tasks sensitive to human amnesia. Behavioral Neuroscience, 99, 22-23.

Zola-Morgan, S., \& SQuiRe, L. R. (1986). Memory impairment in monkeys following lesions limited to the hippocampus. Behavioral Neuroscience, 100, 155-160.

Zola-Morgan, S., Squire, L. R., \& Amaral, D. G. (1989). Lesions of the hippocampal formation but not lesions of the fornix or the mammillary nuclei produce long-lasting memory impairment in monkeys. Journal of Neuroscience, 9, 898-913.

Zola-Morgan, S., Squire, L. R., Clower, R. P., \& Rempel, N. L. (1993). Damage to the perirhinal cortex exacerbates memory impairment following lesions to the hippocampal formation. Journal of Neuroscience, 13, 251-265.

\section{NOTE}

1. Chance levels of performance on the recognition span task change as the numbers of stimuli are presented during a chain of trials. For example, when two items are presented, the probability of choosing the correct by chance is .5; when three items are presented, the probability decreases to .33 . Hence, the probability of making a sequence of correct responses by chance decreases rapidly with the addition of each successive stimulus. The probability of achieving a span of 3 by chance is $.5 \times .333$, or .166 ; the probability of achieving a span of 4 by chance is $.5 \times .33 \times .25$, or .04 . Accordingly, the probabilities of achieving spans from 2 to 4 by chance range from 1.5 to 1.7 .

(Manuscript received April 3, 1998; revision accepted for publication May 24, 1999.) 